\title{
Fundstellen der Entscheidungen des Europäischen Gerichtshofs für Menschenrechte und der früheren Europäischen Kommission für Menschenrechte
}

\section{Europäische Kommission für Menschenrechte}

Von 1960-1974: Bd. 1-Bd. 46: Collection of Decisions of the European Commission of Human Rights (CD);

von 1975-1998: Decisions and Reports Bd. 1-Bd 94 (DR)

seit Bd. 76 aufgeteilt in Series A (Entscheidung in der Orginalfassung); Series B (Entscheidung in der jeweiligen Übersetzung auf englisch oder französisch).

Auch die zu den Berichter der Kommission ergangenen Entscheidungen des Ministerkomitees sind dort wiedergegeben.

\section{Entscheidungen des EGMR}

Die Entscheidungen des Gerichtshofs sind veröffentlicht in englisch/französisch in der amtlichen Sammlung, deren offizieller Name mehrmals wechselte.

Bis 1996: Publications de la Cour européenne de droits de l'homme, Arrêts et décisions, Série A / Publications of the European Court of Human Rights, Judgements and Decisions Series $A^{1}$

hier zitiert Series A Nr. der Entscheidung

1996 bis 1998: Recueil des Arrêts et Décisions/Reports of Judgements and Decisions, hier zitiert Rep. 1997-I

ab 1.11.1998 (Inkrafttreten des 11.ZP) wird diese offizielle Sammlung ausgewählter Entscheidungen, die auch Zuständigkeitsentscheidungen mit erfaßt, offiziell als ECHR zitiert, mitunter findet man aber auch weiterhin die Bezeichnung Reports oder auch Slg, die Fundstelle ist aber jeweils gleich

hier zitiert EGHR 2000-II.

Im Internet sind alle Entscheidungen des alten und des neuen Europäischen Gerichtshofs für Menschenrechte über die Rechtsprechungsdatenbank des Gerichtshofs (Human Rights Documentation „HUDOC") in englischer/französischer Sprache abrufbar (http://hudoc.echr.coe.int). Sie sind dort mit Entscheidungsdatum und Name (ev. abgekürzte Initialen) des Beschwerdeführer leicht zu finden. Auch die Zulässigkeitsentscheidungen der früheren Kommission sind dort für die Zeit von 1986 bis 1998 vollständig und für die Zeit zwischen 1955 und 1986 teilweise erfaßt, desgleichen, soweit veröffentlicht, auch die Berichte der Kommission von 1986 bis 1999.

Dort können u. a. auch chronologische Listen der Entscheidungen mit stichwortartigen Hinweisen auf deren Gegenstand abgerufen werden.

1 Die Series B enthält Sitzungsdokumenten, Schriftsätze u. a.; sie wurde nach dem 104. Band eingestellt. 


\section{Rechtsprechungsübersichten}

Zusammenfassende deutschsprachige Berichte über die Rechtsprechung des EGMR und der früheren EKMR finden sich in mehreren Zeitschriften, so vor allem in EuGRZ

NStZ-RR

Jahrbuch für internationales Recht - JIR (= German Yearbook of International Law GYIL)

Zeitschrift für ausländisches öffentliches Recht und Völkerrecht (ZaöRV). 